\title{
Development of microsatellite markers for the house cricket, Acheta domesticus (Orthoptera: Gryllidae)
}

\author{
YASH MUNNALAL GUPTA", SUPATCHAREE TANASARNPAIBOON, KITTISAK BUDDHACHAT, \\ SURIN PEYACHOKNAGUL, PHATTHARAPORN INTHIM, SOMJIT HOMCHAN ${ }^{\text {v }}$ \\ Department of Biology Faculty of Science, Naresuan University. Phitsanulok, 65000, Thailand. Tel./fax. +66-081-7667, ^email: yash.610@live.com, \\ vvemail: somjitt@nu.ac.th
}

Manuscript received: 16 July 2020. Revision accepted: 12 August 2020.

\begin{abstract}
Gupta YM, Tanasarnpaiboon S, Buddhachat K, Peyachoknagul S, Inthim P, Homchan S. 2020. Development of microsatellite markers for the house cricket, Acheta domesticus (Orthoptera: Gryllidae). Biodiversitas 21: 4094-4099. The house cricket, Acheta domesticus, is one of the species of crickets commonly found in Thailand. Insect breeders in Thailand prefer to breed house cricket as food due to its better taste and popularity among local people. Moreover, largescale breeding industries also breed house cricket to produce cricket-based edible products. Insect breeding industry is growing rapidly and requires primary precaution for sustainable production. To facilitate breeding system to maintain genetic variation in the captive population, we have sequenced the whole genome of A. domesticus to search for simple sequence repeats (SSRs) in order to develop polymorphic microsatellite markers for preliminary population genetic analysis. A total of 112,157 SSRs with primer pairs were identified in our analysis. Of these, 91 were randomly selected to check for amplification of microsatellite polymorphisms. From these, nine microsatellites were used to check genetic variation in forty-five individuals of A. domesticus from the Phitsanulok population (Thailand). These microsatellite markers also showed cross-amplification with other three species of edible crickets, specifically Gryllus bimaculatus, Gryllus testaceus, and Brachytrupes portentosus. The microsatellite markers presented herein will facilitate future population genetic analysis of A. domesticus populations. Moreover, the transferability of these makers would also enable researchers to conduct genetic studies for other closely related species.
\end{abstract}

Keywords: Cross-amplification, microsatellite markers, population genetics, simple sequence repeats

\section{INTRODUCTION}

Understanding the genetic makeup of insects is not straightforward without prior information about each species and its genome (Pereira et al. 2008; Li et al. 2019). Moreover, the analysis of the genetic structure of insect populations requires surveying a large number of samples of each designated species (Hanboonsong et al. 2013). However, obtaining adequate sample collections from the wild can be problematic for several reasons, including the fact that limited numbers of morphological characters are available for distinguishing specific target species from other closely related species in same genus (Gibb et al 2006; Xia et al. 2018). This study focuses on Acheta domesticus (Otte 1994), a common field cricket also known as the house cricket, a species that is widely used as food for human consumption and feeds for pets throughout many countries around Asia (Hutchison et al. 2013).

The commercial uses have created continually rising demand for these insects and increasing numbers of breeders attempting to satisfy requirements. However, these breeders often face the problem of inbreeding depression and bottleneck effects that reduce the genetic diversity of their reared populations. This in turn results in the loss of vitality in the adults and viability of their offspring (Aguiar et al. 2018). In an attempt to avoid these inbreeding problems, house cricket breeders in Thailand often exchange healthy parents from different farms, but they do so without any knowledge of the genetic diversity within or between the different populations. Furthermore, these simple exchanges of healthy parents do not seem to be solving the problem as continual reductions in progeny production continue to be observed (personally communicate with farmers).

One of the challenges here is that despite the popularity of the house cricket in the commercial world, genetic information about these insects is still very limited. However, these crickets are abundant in the environment and very common in Thailand, and so this study was undertaken to understand the genetic structure of house cricket populations. For comprehensive understanding of the genetic structure of such populations, microsatellites are one of the markers most commonly used for population genetic studies (Piotrowska et al. 2016; Hilmarsson et al. 2017). Fortunately, the affordability and accessibility of next-generation sequencing technology have provided a fast-track platform for the identification and development of microsatellite markers in several new species ( $\mathrm{Yu}$ et al. 2011; Kang et al. 2016; Wang et al. 2016; Liu et al. 2017). The use of this technology for whole-genome sequencing can potentially provide thousands of DNA sequences carrying suitable microsatellite loci along with flanking regions to design primers for amplification of specific microsatellite loci using the polymerase chain reaction 
(PCR) (Taheri et al. 2018; Ma et al. 2019). This has allowed researchers to develop genetic markers efficiently and rapidly compared to traditional methods like biotin labelled probes (McKeown et al. 2018). Microsatellites are the most widely used genetic marker because they can be easily genotyped and reproduced for the comparative genetic diversity analysis (Abdul-Muneer 2014). Microsatellite markers provide information that can be used for conserving genetic diversity in the population by marker-assisted selection for the favorable genotype (Seki et al. 2016).

Several studies have previously demonstrated the effective use of microsatellite markers developed from transcriptome and genome for population genetic analysis and to compare genetic variation among and within wild and farmed populations of species (Zheng et al. 2013; Colburn et al. 2017). The studies have shown that farmed populations tend to have less genetic variation compared to wild populations (Wang et al. 2012). However, the genetic structure of farmed and wild house cricket populations is still largely unknown. For this study, we sequenced the whole genome of $A$. domesticus to produce a sequence library to develop microsatellite markers. The identified microsatellite markers were selected and checked for DNA amplification, and amplified loci were selected for population analyses. The use of these microsatellite loci as genetic markers for genetic evaluation of house cricket populations will be beneficial for strategic breeding programs and to maintain the genetic diversity within farmed populations of the house cricket.

\section{MATERIALS AND METHODS}

\section{Sample collection, microsatellite mining, and primer design}

Known specimens of female A. domesticus were collected from farm located at Nakhon Ratchasima, Thailand $\left(14^{\circ} 42^{\prime} 19.6^{\prime \prime} \mathrm{N} \quad 102^{\circ} 27^{\prime} 08.1^{\prime \prime E}\right)$. Legs were dissected from adults to extract DNA using the DNeasy Blood and Tissue Kit (Qiagen, Germany) (Cat No./ID: 69504) for de novo whole-genome sequencing. Genome sequencing was performed by Macrogen, Korea using Illumina based HiSeq x sequencing system. Microsatellite detection was performed using the MIcroSAtellite identification tool (MISA) with parameters of six minimum repeats for dinucleotides and four for tri-, tetra-, penta-, and hexanucleotides. The regions flanking each microsatellite were used to design primers using the Primer3 tool (Untergasser et al. 2012). The parameters used in the Primer3 tool were set as follows: (1) PCR fragment size ranged from 200 to 400 base-pairs (bp), (2) Primer optimal size was $20 \mathrm{bp}$, (3) Annealing temperature ranged from $54^{\circ} \mathrm{C}$ to $60{ }^{\circ} \mathrm{C}$, (4) Optimum primer GC concentration was set to $50 \%$.

\section{Sample collection and microsatellite screening}

Forty-five specimens were collected from Phitsanulok province, Thailand and morphological identification was used to confirm their assignment as A. domesticus. DNA was extracted from leg tissue of individuals using a modified DNA extraction based on a typical phenolchloroform extraction protocol (Nishiguchi et al. 2002).

The preliminary screening for microsatellite polymorphisms was conducted using 91 primer pairs on five randomly selected DNA samples out of the forty-five specimens of $A$. domesticus. The PCRs were conducted using $20 \mu \mathrm{l}$ reaction mixtures as follows: $1 \mathrm{X} \mathrm{Taq}$ buffer, $0.2 \mu \mathrm{Taq}$ DNA polymerase, $0.2 \mathrm{mM}$ dNTPs, $1.5 \mathrm{mM}$ $\mathrm{MgCl}_{2}$ (Thermo Fisher Scientific), $1 \mu \mathrm{M}$ of each primer, $0.1 \mu \mathrm{g} / \mu \mathrm{l}$ Bovine serum albumin (BSA), and $1 \mu \mathrm{l}$ of DNA template followed by nuclease-free water to make up volume to $20 \mu \mathrm{l}$ in reaction tube. All PCR was conducted using Biometra TOne Thermal Cyclers by Analytik Jena, Germany with optimized condition for each primer pairs as follows: a cycle of initial denaturation at $94^{\circ} \mathrm{C}$ for 3 minutes followed by 30 cycles of denaturation, annealing, and extension at $94^{\circ} \mathrm{C}$ for 30 seconds, range from $55^{\circ} \mathrm{C}$ to $58^{\circ} \mathrm{C}$ for 30 seconds, $72^{\circ} \mathrm{C}$ for 40 seconds, respectively with a final extension at $72^{\circ} \mathrm{C}$ for 4 minutes. The primers with positive amplification of $A$. domesticus DNA were also used to check cross-amplification of DNA from Gryllus bimaculatus, Gryllus testaceus, and Brachytrupes portentosus.

All PCR products were analyzed using $1.5 \%$ agarose gel electrophoresis, and only primers with expected PCR product sizes were selected for synthesis (Macrogen Korea) with a 5' forward primer labelled with one of the fluorescent dyes from FAM, HEX, TAMRA. Each fluorescent dye was designated to specific primer according to expected size range of each PCR product to combine DNA products prior to fragment analysis for genotyping of all individuals. The DNA fragment analysis with capillary electrophoresis was done by 1st BASE Fragment Analysis Services, Malaysia. Only polymorphic alleles were analyzed for preliminary population genetic analysis using POPGENE version 1.32 (Yeh and Boyle 1997). MICROCHECKER (Van Oosterhout et al. 2004) was used for checking data to spot any stuttering error. The allele frequency, observed number of alleles, observed and expected heterozygosity, and fixation index was calculated. All loci were tested for linkage disequilibrium.

\section{RESULTS AND DISCUSSION}

The whole-genome de novo sequencing of Acheta domesticus generated 485,490,502 raw DNA reads that were assembled into contigs to search for simple sequence repeats (SSRs). The assembly produced 709,397 contigs (The total number of bases in the contigs, 929,180,478) of nucleotide sequences of $A$. domesticus. This wholegenome data have been deposited at NCBI under the accession number: JAAVVF000000000 (BioProject: PRJNA612585, BioSample: SAMN14377430, Organism: Acheta domesticus YG1991). The MISA identification tool predicted 179,594 sequences containing total 232,179 SSRs. Different SSRs were sorted according to the unit size with a minimum number of repeats. 
Table 1. Locus name, primer sequences with selected dye, Genbank accession number, allele sizes in base pairs (range), primer annealing temperature ( $\mathrm{T}_{\mathrm{A}}$ ), SSR motif, number of alleles (Na), observed heterozygosity $\left(\mathrm{H}_{O}\right)$, and expected heterozygosity $\left(\mathrm{H}_{E}\right)$ values, fixation index $(F)$, and Hardy-Weinberg Equilibrium $P$ values (HWEP) obtained from screening of Acheta domesticus samples from the Phitsanulok population as reported.

\begin{tabular}{|c|c|c|c|c|c|c|c|c|c|c|}
\hline Locus & Primer sequence & GenBank & $\begin{array}{l}\text { Allele size } \\
\text { range (bp) }\end{array}$ & $\begin{array}{l}\mathbf{T}_{\mathrm{A}} \\
\left({ }^{\circ} \mathbf{C}\right)\end{array}$ & SSR & $\mathbf{N a}$ & $\mathbf{H} o$ & $\mathbf{H}_{E}$ & $F$ & $\begin{array}{l}\text { HWE } \\
P\end{array}$ \\
\hline Adome-Penta-2 & $\begin{array}{l}\text { F(HEX)-ACAGCATGTGATGTTTGTGGC } \\
\text { R-TGAAAGTCTTTGGCTGAGATCCT }\end{array}$ & MT311706 & $270-330$ & 57 & (TTTTC)4 & 8 & 0.5366 & 0.7338 & 0.260 & 0.000 \\
\hline Adome-Tri-1 & $\begin{array}{l}\text { F(FAM)-AACGACAAATGCAGCAACCC } \\
\text { R-TAGCTTCCAGGCTGTTCAGG }\end{array}$ & MT311707 & $259-289$ & 57 & (TTG)8 & 7 & 0.4444 & 0.6547 & 0.314 & 0.440 \\
\hline Adome-Tri-6 & $\begin{array}{l}\text { F(HEX)-ACCCCATGAACCCAATTCTGA } \\
\text { R-AATTGCGGCAAGTGGAACTG }\end{array}$ & MT311708 & $329-362$ & 56 & (TGC) 8 & 5 & 0.7333 & 0.6564 & -0.130 & 0.012 \\
\hline Adome-Tetra-10 & $\begin{array}{l}\text { F(FAM)-TCTTCCTGAAATCGTGACTGCA } \\
\text { R-GGTAGCACCTGCAAAGCATC }\end{array}$ & MT311709 & $317-397$ & 56 & (TTAT)6 & 9 & 0.6222 & 0.5046 & -0.247 & 1.000 \\
\hline Adome-Tri-15 & $\begin{array}{l}\text { F(FAM)-GTGAAGGTGTTGATGGCAGC } \\
\text { R-TGCAATGAAACGCAAGGCAA }\end{array}$ & MT311710 & $309-405$ & 57 & (TGG)8 & 11 & 0.6667 & 0.7538 & 0.106 & 0.911 \\
\hline Adome-Di-6 & $\begin{array}{l}\text { F(HEX)-GCAAAGCGATCGTCGTACAC } \\
\text { R-CATCTCTGCTCCACGGTCTC }\end{array}$ & MT311711 & $341-423$ & 57 & $(\mathrm{GA}) 9$ & 14 & 0.4091 & 0.8809 & 0.531 & 0.000 \\
\hline Adome-Tetra-22 & $\begin{array}{l}\text { F(TAMARA)-GAAGAAAGCCCCCGGAGAAA } \\
\text { R-TTACTTTGGTTGTTGCGCCG }\end{array}$ & MT311712 & $262-342$ & 57 & (TGAT)6 & 15 & 0.7556 & 0.9039 & 0.155 & 0.000 \\
\hline Adome-Tetra-15 & $\begin{array}{l}\text { F(FAM)-TTCGGCGGGAATCCATTCAT } \\
\text { R-TTCAAGGTCTGCACAGGCTT }\end{array}$ & MT311713 & $318-366$ & 57 & (TTCT)6 & 10 & 0.5111 & 0.4417 & -0.170 & 1.000 \\
\hline Adome-Tri-18 & $\begin{array}{l}\text { F(FAM)-TTCACTTAGCCAACGTCGCT } \\
\text { R-AAATCACGAACGGGAAGCCT }\end{array}$ & MT311714 & $351-420$ & 57 & $(\mathrm{TCT}) 7$ & 15 & 0.6279 & 0.8668 & 0.267 & 0.001 \\
\hline
\end{tabular}


The SSRs containing nucleotide sequences were used to generate primers for each SSR sequence using defined parameters of the Primer3 tool. These were filtered to generate a primer library of 112,157 SSR primer pairs. From these, 91 randomly selected SSR primer pairs were used to amplify five DNA samples of A. domesticus from the Phitsanulok population. This yielded fourteen out of 91 SSR primer pairs that successfully amplified DNAs of the expected size with clear separate bands for each of the SSR loci. Other 77 SSR primer pairs were discarded from analysis due to poor PCR amplification. Primers for these SSRs were able to cross-amplify microsatellite DNAs from three other species of crickets $(G$. bimaculatus, $G$. testaceus, and B. portentosus). The fourteen SSR sequences were submitted to GenBank (Accession number: MT311706- MT311719).

For population screening, fourteen SSR primer pairs were employed to check for genetic variation and usability of the SSR markers for population genetic studies. The result showed that there were nine potential SSR loci producing alleles with repeats ranging from 5 to 15 in number. The genetic variation for all nine loci is summarized in Table 1 . The observed heterozygosity ranging from 0.4091 to 0.7556 and expected heterozygosity ranging from 0.4417 to 0.9039 . The observed and expected heterozygosity values were computed using Levene (1949) and values were similar to Nei's (1973) expected heterozygosity values. There was no significant linkage disequilibrium found between any pair of loci.

Microsatellite markers are commonly used as DNA markers to understand the genetic structure and diversity of plant and animal populations (Nguluma et al. 2018; Ju et al. 2019).

Acheta domesticus is a highly abundant cricket species in Thailand, and an insect breeding industry is rearing $A$. domesticus to satisfy the commercial need as feed and food (Hanboonsong et al. 2013). However, despite of the popularity of this insect in breeding programs, genetic information on populations of this species is limited. In addition, the breeding programs all suffer from inbreeding related phenomena and reductions in productivity and fitness (Kardos et al. 2016; Bozzuto et al. 2019). These breeding problems cannot be solved only by redesigning the breeding system for the intended species. It is also crucial to have information on the genetic makeup of individuals in this species and the genetic structure of populations. This includes analysis of the genetic variation among and between wild and farmed populations of species like $A$. domesticus.

The present study provides the first set of nine polymorphic microsatellite markers for A. domesticus. These nine loci showed no linkage disequilibrium $(\mathrm{P}<0.007)$. The total number of alleles ranged from 5 to 15 across the nine loci, and that there was considerable variation among collected individuals from the area of Phitsanulok, Thailand. In a previous study of microsatellite development for field cricket species, 27 polymorphic SSR markers were characterized for G. bimaculatus displayed 3 to 12 alleles (Bretman et al. 2008). In contrast, the developed nine SSR markers in present study showed overall high allelic variability (Table 1). The average effective number of alleles (4.580) was lesser than the average observed number of alleles (10.444), which is due to fewer number alleles that have contributed to the allelic frequency at a specific locus.

Forty-five isolates were used in SSR development and initial population assessment. One isolate for Adome-Di-6, two for Adome-Tri-18, and four for Adome-Pen-2, in which no PCR product was detected due to allelic dropout. There was no evidence for SSR scoring error due to stuttering for all nine loci.

Wright's (1978) fixation index $(F)$ was calculated to measure of heterozygote deficiency or excess for each locus. Locus Adome-Tetra-10, Adome-Tetra-15, and Adome-Tri-6 showed negative values for fixation index that indicates the heterozygotes excess for these three loci, and other six loci showed heterozygote deficiency. The average value of the fixation index for all nine loci is 0.121 , which indicates heterozygote deficiency in the Phitsanulok population of house cricket. Three out of nine loci showed high significant deviation $(\mathrm{P}<0.001)$ from Hardy-Weinberg Equilibrium, and these three loci also showed homozygote excess that could be due to the presence of null alleles (Van Oosterhout et al. 2004; Rico et al. 2017; Heidinger et al. 2018). The probability of presence of null alleles was predicted using MICROCHECKER (Van Oosterhout et al. 2004), and result suggested that null alleles may be present at specific locus due to the general excess of homozygotes for most allele size classes as no evidence stuttering or large allele dropout was found. Moreover, the deviation from HWE and heterozygote deficiency could be due to population subdivision in the wild (Garnier-Géré \& Chikhi. 2001; Halligan et al. 2010). In our study, house crickets were captured from wild habitat and presumed to be unrelated, and no matching multilocus genotype was found in isolates from Phitsanulok population.

Extended studies with more wild and farmed populations are required for better understanding of genetic structure of these populations. Moreover, this will undoubtedly help in designing strategies to resolve some of the issues seen in the farmed population suffering from inbreeding depression (Gao et al. 2015; Santos et al. 2016). Many of these problems are known to be caused by low levels of genetic variability in populations (Parra et al. 2018). Future studies might reveal the genetic structure in the farmed A. domesticus population compared to the wild population.

Microsatellite markers that amplify in one species are also sometimes shown to cross-amplify in related species (Iorgu et al. 2013; Leite et al. 2016). The novel SSR markers we identified in A. domesticus demonstrated the transferability to the three other Orthopteran species; $G$. bimaculatus, $G$. testaceus, and $B$. portentosus. This suggests that it will be possible to use these SSR markers to conduct population genetic studies for these species as well. The transferability would open the possibility to use developed SSR markers for other related species from the family Gryllidae (crickets) (Bretman et al. 2008; Tantrawatpan et al. 2011) since these genetic markers are 
robustly used for evaluating genetic diversity (Zhou et al. 2016) and understanding the genetic structure (Hutchison et al. 2016) and status of different populations. In a previous study, 45 polymorphic microsatellite markers were developed for wood cricket, Nemobius sylvestris (Orthoptera: Gryllidae) to assist future studies, only 2 out of 34 microsatellite markers showed cross-amplification with field cricket $G$. bimaculatus (Orthoptera: Gryllidae) (Vanhala et al. 2008). In present report, all 9 microsatellite markers showed positive cross-amplification with $G$. bimaculatus. These indicate the high potential of developed SSR markers for phylogenetic analysis. This could be also transferable with $N$. sylvestris and other related cricket' species that fall into the classification between $A$. domesticus and N. sylvestris. For the case of the house cricket, A. domesticus, these novel SSRs might also unable to answer questions regarding the genetic status of cultivated house cricket in breeding centers and their genetic kinship to wild populations. This information should be useful in designing strategies for our outcrossing to introduce new genetic material into captive breeding populations to reduce inbreeding effects.

The present study provides nine SSR markers which will assist marker-based selection for healthy parents for breeding purposes. SSR markers will also facilitate and improve the breeding system of $A$. domesticus and other related species, specifically G. bimaculatus, G. testaceus, and $B$. portentosus. These markers will assist future population genetic studies for this species to provide more definitive information.

\section{ACKNOWLEDGEMENTS}

We would like to thank Prof. David Haymer for polishing English and giving valuable comments. This research has been supported by Centre of Excellence on Biodiversity, Office of Higher Education (BDC-PG2160006), and Department of Biology, Naresuan University, Thailand.

\section{REFERENCES}

Abdul-Muneer PM. 2014. Application of microsatellite markers in conservation genetics and fisheries management: Recent advances in population structure analysis and conservation strategies. Genet Res Int. DOI: 10.1155/2014/691759.

Aguiar JD, Gomes PF, Hamoy IG, Santos SE, Schneider H, Sampaio I. 2018. Loss of genetic variability in the captive stocks of tambaqui, Colossoma macropomum (Cuvier, 1818), at breeding centres in Brazil, and their divergence from wild populations. Aquac Res 49 (5): 1914-1925. DOI: $10.1111 /$ are.13647.

Bozzuto C, Biebach I, Muff S, Ives AR, Keller LF. 2019. Inbreeding reduces long-term growth of Alpine ibex populations. Nat Ecol Evol 3 (9): 1359-1364. DOI: 10.1038/s41559-019-0968-1.

Bretman A, Dawson DA, Horsburgh GJ, Tregenza T. 2008. New microsatellite loci isolated from the field cricket Gryllus bimaculatus characterized in two cricket species, Gryllus bimaculatus and Gryllus campestris. Mol Ecol Resour 8 (5): 1015-1019. DOI: 10.1111/j.17550998.2008.02139.x.

Colburn BC, Mehlenbacher SA, Sathuvalli VR. 2017. Development and mapping of microsatellite markers from transcriptome sequences of European hazelnut (Corylus avellana L.) and use for germplasm characterization. Mol Breed 37 (2): 16. DOI: 10.1007/s11032-0160616-2.

Gao B, Liu P, Li J, Wang Q, Han Z. 2015. Effect of inbreeding on growth and genetic diversity of Portunus trituberculatus based on the fullsibling inbreeding families. Aquacul Int 23 (6): 1401-1410. DOI: 10.1007/s10499-015-9892-9.

Garnier-Géré P, Chikhi L. 2001. Population subdivision, Hardy-Weinberg equilibrium and the Wahlund effect. Wiley Online Library, eLS. DOI: 10.1002/9780470015902.a0005446.pub3

Gibb TJ, Oseto CY, Oseto C. 2006. Arthropod Collection and Identification: Laboratory and Field Techniques, Elsevier Academic Press, New York, USA.

Halligan DL, Oliver F, Eyre-Walker A, Harr B, Keightley PD. 2010. Evidence for pervasive adaptive protein evolution in wild mice. PLoS Genet 6 (1): e1000825. DOI: 10.1371/journal.pgen.1000825.

Hanboonsong Y, Jamjanya T, Durst PB. 2013. Six-legged Livestock: Edible Insect Farming, Collection and Marketing in Thailand. FAO Regional Office for Asia and the Pacific, Bangkok. [www.fao.org/docrep/017/i3246e/i3246e.pdf].

Heidinger IM, Hein S, Feldhaar H, Poethke HJ. 2018. Biased dispersal of Metrioptera bicolor, a wing dimorphic bush-cricket. Insect Sci 25 (2): 297-308. DOI: 10.1111/1744-7917.12412.

Hilmarsson HS, Hytönen T, Isobe S, Göransson M, Toivainen T, Hallsson JH. 2017. Population genetic analysis of a global collection of Fragaria vesca using microsatellite markers PLoS One 12 (8): e0183384. DOI: 10.1371/journal.pone.0183384.

Hutchison N, Leberg P, Lance RF, Goodacre S. 2013. Development of novel microsatellite markers for the secret cave cricket, Ceuthophilus secretus. J Insect Sci 13 (1). DOI: 10.1673/031.013.6401.

Hutchison NL, Lance RF, Pekins CE, Noble ME, Leberg PL. 2016. Influence of geomorphology and surface features on the genetic structure of an important trogloxene, the secret cave cricket (Ceuthophilus secretus). Conserv Genet 17 (4): 969-983. DOI: 10.1007/s10592-016-0836-3.

Iorgu EI, Popa OP, Krapal A-M, Popa LO. 2013. Isolation and characterization of microsatellite loci for Stys's bush-cricket, Isophya stysi, and cross-species amplification in closely related species from the Phaneropteridae family. J Insect Sci 13 (1): $55 . \quad$ DOI: 10.1673/031.013.5501.

Ju Y, Liu H, Rong M, Zhang R, Dong Y, Zhou Y, Xing X. 2019. Genetic diversity and population genetic structure of the only population of Aoluguya Reindeer (Rangifer tarandus) in China. Mitochondrial DNA Part A 30 (1): 24-29. DOI: 10.1080/24701394.2018.1448081.

Kang T, Han S, Park S. 2016. Development of 12 microsatellite markers in Dorcus titanus castanicolor (Motschulsky, 1861) (Lucanidae, Coleoptera) from Korea using next-generation sequencing. Int $\mathrm{J}$ Mol Sci 17 (10): 1621. DOI: 10.3390/ijms17101621.

Kardos M, Taylor HR, Ellegren H, Luikart G, Allendorf FW. 2016. Genomics advances the study of inbreeding depression in the wild. Evol Appl 9 (10): 1205-1218. DOI: 10.1111/eva.12414.

Leite N, Correa A, Alves-Pereira A, Campos J, Zucchi M, Omoto C. 2016. Cross-species amplification and polymorphism of microsatellite loci in Helicoverpa armigera and Helicoverpa zea (Lepidoptera: Noctuidae) in Brazilian cropping systems. Genet Mol Res 15: 1-12. DOI: $10.4238 / \mathrm{gmr} .15027890$.

Levene H. 1949. On a matching problem arising in genetics. Ann Math Stat 20 (1): 91-94. DOI: 10.1214/aoms/1177730093.

Li F, Zhao X, Li M, He K, Huang C, Zhou Y, Li Z, Walters JR. 2019. Insect genomes: Progress and challenges. Insect Mol Biol 28 (6): 73958.

Liu T, Ke F, You S, Chen W, He W, You M. 2017. Isolation and characterization of microsatellite loci for Cotesia plutellae (Hymenoptera: Braconidae). Insects 8 (2): 63 . DOI: 10.3390/insects8020063.

Ma L, Cao LJ, Gong YJ, Hoffmann AA, Zeng AP, Wei SJ, Zhou ZS. 2019. Development of novel microsatellites for population genetic analysis of Phenacoccus solenopsis Tinsley (Hemiptera: Pseudococcidae) based on genomic analysis. Int J Biol Macromol 121: 1135-1144. DOI: 10.1016/j.ijbiomac.2018.10.143.

McKeown N, Harvey D, Healey A, Skujina I, Cox K, Gange AC, Shaw P. 2018. Isolation and characterisation of the first microsatellite markers for the European stag beetle, Lucanus cervus (Coleoptera: Lucanidae). Eur J Entomol 115: 620-623. DOI: 10.14411/eje.2018.059. 
Nei M. 1973. Analysis of gene diversity in subdivided populations. Proceeding the National Academy of Sciences 70 (12): 3321-3323. DOI: $10.1073 /$ pnas.70.12.3321.

Nguluma AS, Huang Y, Zhao Y, Chen L, Msalya G, Lyimo C, Guangxin E, Chenyambuga SW. 2018. Assessment of genetic variation among four populations of Small East African goats using microsatellite markers. S Afr J Anim Sci 48 (1): 117-127. DOI: 10.4314/sajas.v48i1.14.

Nishiguchi MK, Doukakis P, Egan M, Kizirian D, Phillips A, Prendini L, et al. 2002. DNA isolation procedures. Techniques in Molecular Systematics and Evolution: Springer 249-287.

Otte D. 1994. Crickets (Grylloidea). Orthoptera species file, 1. Orthopterists' Soc. and Acad. Nat. Sci, Philadelphia, USA.

Parra GJ, Cagnazzi D, Jedensjö M, Ackermann C, Frere C, Seddon J, Nikolic N, Krützen M. 2018. Low genetic diversity, limited gene flow and widespread genetic bottleneck effects in a threatened dolphin species, the Australian humpback dolphin. Biol Conserv 220: 192 200. DOI: 10.1016/j.biocon.2017.12.028.

Pereira F, Carneiro J, Amorim A 2008. Identification of species with DNA-based technology: Current progress and challenges. Recent Pat DNA Gene Seq 2 (3): 187-200. DOI: 10.2174/187221508786241738

Piotrowska MJ, Ennos RA, Fountaine JM, Burnett FJ, Kaczmarek M, Hoebe PN. 2016. Development and use of microsatellite markers to study diversity, reproduction and population genetic structure of the cereal pathogen Ramularia collo-cygni. Fungal Genet Biol 87: 64-71. DOI: 10.1016/j.fgb.2016.01.007.

Rico C, Cuesta JA, Drake P, Macpherson E, Bernatchez L, Marie AD. 2017. Null alleles are ubiquitous at microsatellite loci in the wedge clam (Donax trunculus). Peer J (5): e3188. DOI: 10.7717/peerj.3188.

Santos CHA, Santana GX, Sá Leitão CS, Paula-Silva MN, Almeida-Val VMF. 2016. Loss of genetic diversity in farmed populations of Colossoma macropomum estimated by microsatellites. Anim Genet 47 (3): 373-376. DOI: 10.1111/age.12422.

Seki Y, Wada K, Kikkawa Y. 2016. Practical applications of microsatellite markers in goat breeding. Microsatellite Markers. DOI $10.5772 / 64780$.

Taheri S, Lee Abdullah T, Yusop MR, Hanafi MM, Sahebi M, Azizi P, Shamshiri RR 2018. Mining and development of novel SSR markers using next-generation sequencing (NGS) data in plants. Molecules 23 (2): 399. DOI: 10.3390/molecules23020399.

Tantrawatpan C, Saijuntha W, Pilab W, Sakdakham K, Pasorn P, Thanonkeo S, Thiha, Satrawaha R, Petney T. 2011. Genetic differentiation among populations of Brachytrupes portentosus
(Lichtenstein 1796) (Orthoptera: Gryllidae) in Thailand and the Lao PDR: The Mekong River as a biogeographic barrier. Bull Entomol Res 101 (6): 687. DOI: 10.1017/S000748531100023X.

Untergasser A, Cutcutache I, Koressaar T, Ye J, Faircloth BC, Remm M, Rozen SG. 2012. Primer3-new capabilities and interfaces. Nucleic Acids Res 40 (15): e115-e115. DOI: 10.1093/nar/gks596.

Van Oosterhout C, Hutchinson WF, Wills DP, Shipley P. 2004. MICRO-CHECKER: Software for identifying and correcting genotyping errors in microsatellite data. Mol Ecol Notes 4 (3): 535538. DOI: $10.1111 /$ j.1471-8286.2004.00684.x

Vanhala T, Cottrell J. 2008. Development of microsatellite markers for the wood cricket, Nemobius sylvestris (Orthoptera: Gryllidae). Molecular Ecol Resour 8 (6): 1340-1343. DOI: 10.1111/j.17550998.2008.02269.x

Wang L, Shi X, Su Y, Meng Z, Lin H. 2012. Loss of genetic diversity in the cultured stocks of the large yellow croaker, Larimichthys crocea, revealed by microsatellites. Int J Mol Sci 13 (5): 5584-5597. DOI: 10.3390/ijms13055584

Wang YZ, Cao LJ, Zhu JY, Wei SJ. 2016. Development and characterization of novel microsatellite markers for the peach fruit moth Carposina sasakii (Lepidoptera: Carposinidae) using nextgeneration sequencing. Int $\mathrm{J}$ Mol Sci 17 (3): 362. DOI: 10.3390/ijms 17030362

Wright S. 1978. Evolution and the Genetics of Populations, Volume 4: Variability Within and Among Natural Populations. University of Chicago Press, USA.

Xia D, Chen P, Wang B, Zhang J, Xie C. 2018. Insect detection and classification based on an improved convolutional neural network. Sensors 18 (12): 4169 . DOI: 10.3390/s18124169

Yeh F, Boyle TJB. 1997. Population genetic analysis of co-dominant and dominant marker and quantitative traits. Belgian J Bot 130: 129-57.

Yu JN, Won C, Jun J, Lim Y, Kwak M. 2011. Fast and cost-effective mining of microsatellite markers using NGS technology: An example of a Korean water deer Hydropotes inermis argyropus. PloS One 6 (11): e26933. DOI: 10.1371/journal.pone.0026933

Zheng X, Pan C, Diao Y, You Y, Yang C, Hu Z. 2013. Development of microsatellite markers by transcriptome sequencing in two species of Amorphophallus (Araceae). BMC Genomics 14 (1): 490. DOI: 10.1186/1471-2164-14-490.

Zhou ZJ, Kou XY, Qian LY, Liu J. 2016. Transcriptome profile of Chinese bush cricket, Gampsocleis gratiosa: A resource for microsatellite marker development. Entomol Res 46 (3): 197-205. DOI: $10.1111 / 1748-5967.12165$. 